\title{
Reflexiones sobre la retórica desde la hermenéutica ${ }^{1}$
}

\section{Introducción}

En este trabajo me propongo hacer resaltar algunas semejanzas de la retórica con la hermenéutica ( $y$, de manera indirecta, con la pragmática), ${ }^{2}$ siguiendo a Paul Ricoeur. En la tradición hermenética se ha visto la analogía que existe entre estas disciplinas del lenguaje, y el compararlas nos podrá aleccionar acerca de su origen, su estructuración dinámica y su objetivo o finalidad. En todo caso, creo que resultará muy esclarecedor para el estudioso de estas disciplinas conocer sus semejanzas y diferencias, eso ayudará a dar a una y a otra una mayor y mejor delimitación.

\section{El origen de la retórica y de la hermenéutica}

Hans Georg Gadamer ${ }^{3}$ y Paul Ricoeur han vinculado a la retorica con la hermenéutica. De hecho, este último coloca a la retórica,

${ }^{1}$ Deseo agradecer su lectura crítica' de este trabajo a Helena Beristáin y a Ana Goutman.

${ }^{2}$ La hermenéutica y la pragmática son disciplinas que coinciden en muchas cosas. La hermenéutica, surgida de la filosofía, trata de interpretar el significado de un texto, pero sabe que no logrará apresar de manera completamente objetiva el mensaje del autor, porque en la transacción interpretativa se introducirá la subjetividad del lector o intérprete, del hermeneuta. En cambio, la pragmática, disciplina que configura una rama de la semiótica, pretende confiar en que se puede lograr la objetividad y rescatar el significado del autor (el speaker's meaning), esto es, la intencionalidad del hablante o autor de un texto, y no sólo la intencionalidad subjetiva del hermeneuta.

${ }^{3} \mathrm{He}$ tratado las ideas de Gadamer sobre la retórica en M. Beuchot, "Re- 
junto con la poética y la hermenéutica misma, entre las disciplinas que versan sobre discursos en los que el sentido se articula en unidades más amplias que el enunciado ( $y$, obviamente, más que la palabra). El sentido ha de buscarse en esos discursos atendiendo a unidades más complejas, que configuran textos. En una pieza retorica y en un poema sólo se pueden captar las múltiples intenciones significativas del autor hasta que se toma en cuenta todo el texto. Podríamos decirlo así: una unidad discursiva poética, un poema, no exhibe su sentido al atender solamente a algunas palabras o a algunas de las oraciones de que consta, sino que lo da en unidades más grandes. Una unidad discursiva retórica, un "retorema" o "retoriquema", o como se quiera llamar —así lo llama Ricoeur - sólo alcanza su objetivo de comunicación y de persuasión con más elementos de los que bastarían para entender lo que dice un enunciado científico o filosófico que no padece tanta equivocidad, que tiende más a la univocidad. La misma hermenéutica adquiere su lugar más allá de la palabra (en la que se centraba el estructuralismo) y el enunciado (en el que se centraba la filosofía analítica del lenguaje), y avanza hacia textos más complejos. Así también la retórica. Ella analiza y norma, describe y prescribe, el discurso en el que no sólo va involucrada la argumentación, sino la emoción. Es un discurso híbrido, tiene que afrontar una semiosis o comunicación que esconde muchos recovecos, que impregna de emotividad a las palabras y las frases, y que no arguye únicamente a la razón, sino también al corazon; por lo tanto, no solo puede disfrazar al sofista que redarguye falazmente, sino al seductor que manipula los sentimientos.

Sabemos que la oratoria es una de las más antiguas disciplinas de la utilización discursiva del lenguaje. Esto es algo que me parece importante, porque nos muestra la vinculación de la retórica con el razonamiento humano. Es algo que vincula a la vez a la historia de la retórica con la historia de la hermenéutica. ${ }^{4}$ También

tórica y hermenéutica en H. G. Gadamer", en Semiosis, 18 (1987), pp. 141148. Por eso me concentraré ahora en Paul Ricoeur.

4 Ver P. O. Kristeller, Philosophy and Rhetoric from Antiquity to the Re- 
sabemos que ambas disciplinas se sitúan originalmente en los pleitos por los terrenos, por la tierra. Eran polémicas que requerían la interpretación de la ley y la interpretación de las intervenciones de los protagonistas, para encontrar las fisuras argumentativas y emocionales por donde les pudiera entrar el discurso. Eran pugnas por el espacio vital, una de las cosas más primitivas y perentorias para el hombre. Y allí la retórica era el discurso para ubicarse, para demarcar los propios terrenos y territorios. Es el hombre definiéndose (demarcándose) por el razonamiento, el discurso. No en balde la definición lógica (horismós) es también el término (horos) que figura en la enunciación, y tienen parentesco desde su origen en la demarcación del terreno (horizoo) y la orografía. Por eso aquí Ricoeur tiene muy en cuenta la aportación de Perelman: que siempre se ubica uno frente al público o la audiencia que lo escucha. De alguna manera se podría decir que el primer tópico o "Iugar" es en el que uno se sitúa, dónde uno se coloca, desde donde se habla y con quiénes se habla. En ese papel de ubicación, de crearse lugar, es en donde se sitúa lo que Perelman llama el Imperio Retórico.

Según Ricoeur, el imperio retórico comienza a desplegarse a partir de algo muy concreto, para llegar a tener la pretensión de abarcarlo todo, el campo entero del uso discursivo del lenguaje. Esto - aunque no lo señala Ricoeur - creo que se da porque la retórica abarca más que la lógica y la dialéctica o tópica; por lo tanto, hay cosas de la lógica o de la dialéctica que pueden abordarse con la retórica, pero no a la inversa. Todo podría, pues, en principio, ser tratado retóricamente. Y se diversifica por la situación típica del discurso, por ejemplo, por la finalidad que tiene la pieza oratoria. Así, Aristóteles distingue tres clases de retórica según tres contextos: deliberativa, la que tiene como objetivo convencer acerca de lo conveniente para la república; judiciaria, la que quiere convencer de un caso jurídico; y epidíctica, la que tiene como fin señalar alguna virtud o algún vicio, exaltar o vili-

naissance, Columbia University Press, 1979, pp. 15 ss. Ver también R. Barthes, La retórica antigua, Barcelona: Ediciones Buenos Aires, 1982, pp. 12 ss. 
pendiar a alguien. Dada esa amplitud que tiene, la retórica fue la que ejercio desde un principio las funciones de la hermenéutica. ${ }^{5}$

La retórica se sitúa a mitad de camino entre la necesidad, objeto de la lógica, y la pura contingencia, objeto de la sofística. Corrió el peligro de quedar en las manos de los sofistas, los cuales le daban el estatuto de arma e instrumento para manejar la equivocidad y poder sacar provecho para el que lo utiliza hábilmente. Por lo cual de ningún modo podía atender a la necesidad lógica, dado que tenía como propio lo verosímil, lo concreto y contingente, principalmente lo que tenía que ver con la praxis de la polis. La retorica puede plantcarse en un terreno intermedio, no el de la verdad (que alcanza la lógica) ni el del error y la falacia (que constru-

- ye la sofística), sino el de lo verosímil. Es como el medio que constituye la analogía con la equivocidad y la univocidad, sólo que la analogía no se contenta con lo verosímil, sino que aspira a la verdad (aunque no sólo a nivel lógico-sintáctico, sino más bien semántico y pragmático), pero que involucra lo verosímil como una de sus partes. Y, así, evita el equívoco y la falacia, y procura sujetar el discurso a lo más apegado que se alcance de la lógica. Se inclina hacia la lógica, evitando que el discurso caiga en la equivocidad y la falacia, a cuyos bordes se inclina peligrosamente. "Esta descripción del hogar de la retorica -dice Ricoeur- hace aparecer de inmediato la ambigüedad. La retórica jamás ha dejado de oscilar entre una amenaza de decadencia y la reivindicación totalizante en virtud de la cual ambiciona igualarse a la filosofía". ${ }^{6}$

3. El desarrollo de la acción retórica y de la acción hermenéutica

Ricoeur está de acuerdo con Perelman en que el discurso retórico es eminentemente un discurso situado; tiene que tomar en cuenta,

${ }^{5}$ M. Ferraris, Storia dell'ermeneutica, Milán: Bompiani, 1988, pp. 12-13.

' P. Ricoeur, "Rhétorique-Poétique-Herméneutique", en M. Meyer (ed.), De la métaphysique à la rhétorique, Bruselas: Eds. de l'Université de Bruxelles, 1986, p. 146. 
como el que más, a sus destinatarios. El orador no puede argumentar en el vacío, sino que ha de ponerse en sintonía con sus oyentes, su auditorio. Si la logica puede argumentar como si tuviera un auditorio universal, casi abstracto, la retórica tiene que darse en función de un auditorio más restringido, más particularizado, muy concreto. No sólo argumenta hacia el intelecto, sino también hacia el afecto. No sólo muestra la validez de los razonamientos, sobre todo persuade y convence haciendo uso de lo que se ha llamado "las otras razones" (Pascal), a saber, las del corazón. Como un aspecto de la adecuación que tiene que lograr el orador con su auditorio, se presenta el uso de lugares comunes o elementos argumentativos que son aceptados y compartidos por los concurrentes, por los circunstantes, se trata de una comunicacion altamente circunstanciada.

Pero Ricoeur nos hace observar que la retorica tiene un doble peligro o riesgo de excesos. Por un lado, se dedica a exaltar; por otro, a rebajar. Así la retórica puede estar al servicio de lo que se ha llamado "ideología" (en el sentido marxista de falsa conciencia). Otra vez parece estar expuesta a quedar en manos de los sofistas que quieran aprovecharse de ella. Es donde Ricoeur señala el peligro de perversión y de sublimación. Curiosamente, si atendemos al significado que da Freud a los términos empleados por Ricoeur, podemos damos cuenta de que siempre hay el riesgo de la perversión en el sujeto, pero precisamente una de las cosas que evita ese curso desviado de los impulsos hacia la perversión es la sublimación; la sublimación da a los impulsos una satisfacción que no es ciertamènte la original y más propia, pero es una satisfacción sustitutiva y hasta paliativa que, porlo menos, reorienta y reencauza ese flujo impulsivo de una manera más noble y adecuada, que evita caer en la perversión. En ese sentido, podemos decir que, no la exaltación desmedida y sofística, pero sí la sublimación que evite la perversión, podrá hacer que la retórica se transforme en un instrumento que, sin caer en la ideologización, pueda orientar en cuanto a la marcha de la praxis en la polis, y, sobre todo, en la búsqueda del bien común, no ciertamente sólo del bien particular. 
Sin embargo, este no es el principal peligro que detecta Ricoeur en la retórica, sino la pretensión de abarcar el campo filosófico, y así querer equipararse a la filosofía. Podrfamos decir que hay un riesgo de que en el imperio retórico se quiera encerrar a la filosofía, que la retórica ejerza un imperialismo tal y tan intemperante, que quiera devorar al todo de la filosofía. En efecto, como hemos dicho, la retórica puede llegar a donde no alcanzan la logica ni la dialéctica. Por ejemplo, como lo señala Ricoeur, sólo la retorica puede argumentar a favor de las proposiciones más generales o primeros principios de la filosofía. Allí no llega la lógica; eso supondría que hay otros principios anteriores desde los cuales se podría efectuar la deducción. La dialéctica apenas lo podría hacer; pero, como dichos principios están muy conectados con las creencias emotivas del individuo, poco a poco se va derivando a la retórica. Como Perelman y, sobre todo, Henry W. Johnstone Jr. lo han hecho ver, los primeros principios no pueden ser demostrados por la logica, y sólo la retórica podría hacerse cargo de defenderlos. ${ }^{7}$ En ello ve Ricoeur, según lo notamos, un peligro de que la retórica quiera equipararse a la filosofía misma. Si esas proposiciones primeras de la lógica y de la metafísica sólo pueden apoyarse en la retórica, ésta tendría -como Pascal llegó a proponer- ${ }^{8}$ un papel muy cercano a la metafísica, como su asistente argumentativo y, casi, como un émulo de la propia metafísica.

\section{La finalidad de la retórica y de la hermenéutica}

Una de las cosas que, según Ricoeur, la retorica no puede dejar de lado es justamente su origen, pero otra más importante es su finalidad. Entre el origen y el fin se tiende la intencionalidad, la

7 Ver H. W. Johnstone Jr., Validity and Rhetoric in Philosophical Argument. An Outlook in Transition, University Park, Pa.: The Dialog Press of Man and World, 1978, pp. 5-12.

- Ver Morot-Sir, La metafísica de Pascal, Buenos Aires: Ed. El Ateneo, 1977. 
intención del rhetor. La intención era en primer lugar llegar a unos interlocutores más o menos bien determinados. Y, en segundo lugar, persuadir de un contenido del discurso que se presentaba a esos interlocutores. Sobre esto dice Ricoeur: "En cuanto a la finalidad de la persuasión, no podría ser sublimada al punto de fusionarse con el desinterés de la discusión filosófica auténtica. No tengo, ciertamente, la ingenuidad de creer que los filosofos se libran no sólo de molestias, sino también de la patología que infecta nuestros debates. La perspectiva de la discusión filosófica, si está a la altura de lo que se acaba de llamar auditorio universal, trasciende el arte de persuadir y de agradar, bajo sus formas más honestas, que prevalece en las situaciones antedichas". Así pues, aun cuando la retorica sirve argumentativamente a la filosofía, no se equipara con ella, ni le es coextensiva. Una y otra tienen un origen y una finalidad diversas.

Ricoeur se interesa asimismo en señalar algunas de las relaciones que mantiene la retórica con la poética y la hermenéutica. La retorica tiene en común con la hermenéutica que esta última debe también argumentar, a saber, hay que explicar lo más posible para comprender lo más posible; $y$, además, tiene que argumentar para decidir entre interpretaciones rivales, diríamos que para decidir el conflicto de las interpretaciones, como lo llama el mismo Ricoeur o, como dice Gadamer, también la hermenéutica, o más propiamente el hermeneuta, tiene que convencer, persuadir de su interpretación, o de su tradición. Sin traicionar el modo como describe este conflicto Ricoeur, podemos volver a traer la comparación con là analogía. No se trata de defender una equivocidad hermenéutica en la que todas las interpretaciones son valederas, ni tampoco de lograr la univocidad hermenéutica según la cual sólo hay una única interpretación posible; pero sí se puede hablar de que la hermenéutica alcanza una situación analógica, en la que hay una interpretación principal y otras menos atinadas o ricas. Como en la analogía hay un princeps analogatum o primum ana-

${ }^{9}$ P. Ricoeur, art. cit., p. 147. 
logatum, i. e., un analogado principal, y analogados secundarios, así también en la situación hermenéutica creo que se puede hablar de una interpretación principal, o privilegiada, o mejor, y otras secundarias o menores, por muy complementarias que sean. Se puede decidir cuáles entre ellas se acercan más a la verdad, esto es, son más verosímiles, y así tenemos la verosimilitud -al igual que en la retórica - instalada en la hermenéutica. La analogicidad pertenece de manera eminente a la retorica y la hermenética.

Efectivamente, el propio Ricoeur alude a la semejanza del trabajo hermenéutico con el retórico en cuanto al manejo de la analogía, y es que el trabajo de ambas es semejante a, o coincide con, esa parte de la analogía que es la metáfora. Ricoeur ve que la comprensión y comunicación de la metáfora es de doble sentido, y en eso constituye un modelo o paradigma del trabajo interpretativo, esto es, de la hermenéutica. Es sabido que la retórica -al igual que la poética - tiene que ver con los tropos y las figuras literarios, entre ellos eminentemente la metáfora. ${ }^{10}$ Esto resulta paradigmático porque nos muestra que tanto la hermenéutica como la retórica emplean un discurso polisémico, de muchos sentidos. En la comunicación retórica aparece, de hecho, el ornato o la elocución amplificada, que juega con la presentación del mensaje en diversas formas, en varios modos de presentación, los cuales corresponden a los sentidos (asi los definí Frege: modos de presentación) y pueden transmitir de distintas maneras una misma referencia, y eso es muy importante para la oratoria, pues cabe presentar (pragmáticamente) de una manera mejor que otra el mismo contenido semántico.

Se podrá dudar de si la poesía tiene referencia, o si alude a un mundo; Ricoeur dice que sí, a saber, el mundo del texto. Lo mismo se puede decir de la retórica; pero se volverá a objetar que el mundo del texto no es un objeto de referencia como el mundo real; mas Ricoeur responde que la hermenética es la mediación

${ }^{10}$ Ver Idem, La metáfora viva, Madrid: Eds. Europa, 1983. 
entre el mundo del texto y "lo que convencionalmente llamamos realidad, para redescribirla". ${ }^{11}$ Este encuentro del mundo del texto con el mundo real es la última función de la imaginación creativa o productora en el ejercicio de la lectura.

Mas, junto a estas coincidencias, hay que preservar -pide $\mathrm{Ri}$ coeur- las diferencias, tanto de origen como de finalidad, de fin. No hay una superdisciplina que cubra el campo de la retórica, la poética y la hermenéutica. Se han visto algunas intersecciones entre ellas; pero tienen su autonomía y especificidad. "La retórica sigue siendo el arte de argumentar en vistas a persuadir a un auditorio de que una opinión es preferible a su rival. La poética permanece siendo el arte de construir intrigas en vistas a ampliar el imaginario individual y colectivo. La hermenética permanece como el arte de interpretar los textos en un contexto distinto del de su autor y de su auditorio inicial, en vistas a descubrir nuevas dimensiones de la realidad. Argumentar, configurar, redescribir, tales son las tres operaciones mayores cuya respectiva mirada totalizadora vuelve excluyentes la una de la otra, pero que la finitud de su sitio original condena a la complementariedad". ${ }^{12}$

Por tanto, hemos visto que la retórica tiene un fuerte componente de significación hermenéutica y pragmática. La interpretacion, en vistas a recoger el sentido del hablante o escritor (pragmática), así como a adecuarlo al significado del oyente o lector (hermeneutica), es necesaria a la comunicación retórica. La utilización de tropos, figuras, ironías, implicaturas y, en fin, todas los actos ilocucionarios que conlleva - no en balde se le llamaba antiguamente elocución o ilocución a la acción retórica principalexige que la intervención de los usuarios del discurso en el acto comunicativo sea de suma importancia. Y para ello se requiere de la hermenéutica y la pragmática, disciplinas y artes de la significación viva y actuante. ${ }^{13}$

${ }^{11}$ Idem, art. cit., p. 154.

12 Ibid, p. 155 .

${ }^{13}$ Sobre la hermenéutica de Ricoeur puede verse M. Beuchot, Hermenéutica, lenguaje e inconsciente, Universidad Autónoma de Puebla, 1989. 


\section{Retorica, hermenéutica, filosofía y pragmática}

De hecho, esto se ha contemplado a lo largo de la historia, en la que se entrecruzan la filosofía, la retórica, la hermenéutica y la pragmática. Nuestra atención a la obra de Ricoeur ha resultado rica en enseñanzas. Todo ello parece aleccionarnos acerca del carácter pragmático y hermenéutico de la argumentación retorica. Esto, por lo demás, se ve a lo largo de la historia de la filosofía y de la retórica.

Ya en Aristóteles se veía que está íntimamente unida la retórica a la psicología, ya que él trata de embonar la argumentación con la psicagogia (o movimiento de las emociones, el lado psico16 gico de la oratoria). Y aun nos enseña que toda argumentación filosofica de principios es en el fondo e inevitablemente retórica. En efecto, cuando se discuten principios metafísicos o muy elevados y primeros, sólo se puede usar una prueba indirecta y reductiva, una especie de ad hominem, que pertenece a la retorica (como lo dice del principio de no contradicción en la Metaphysica).

Después, Boecio insistió en la importancia de los tópicos retóricos que, a semejanza de los dialécticos, proceden por las opiniones comunes, aceptadas, plausibles. Pero lo aceptado o común varía y depende del contexto en el que uno se mueva; encierra la consideración pragmática de lo que el otro o los otros conceden; se trata de una verdad pragmática o pragmatista (p. ej., en el sentido de Austin y Strawson).

En plena Edad Media, Robert Kilwardby recalco la semejanza de la retórica con la dialéctica o lógica. Esto es, la retórica nunca puede perder su componente argumentativo, so pena de caer en un juego meramente sentimental de seducción engañosa y sofística. Pero esa argumentación debe procurarse interpretando lo que puede aceptar el conjunto de oyentes, los destinatarios. Nuevamente es la pragmática la que nos asegura el carácter argumentativo y no solamente locuaz de la retorica, a través de las condiciones cognoscitivas de la argumentación concreta y viva. 
También san Vicente Ferrer (quien fuera un eminente logico escolástico) señaló esa presencia fuerte de la argumentación pragmática en la retorica. Lo ejemplifica en su propia práctica oratoria. Tuvo que atender muy inteligentemente a las interacciones psicológicas y sociológicas, religiosas y culturales que conforman la dimensión pragmática de ese acontecimiento semiótico y comunicativo que es el intercambio oratorio. Pues, si no, hubiera incurrido constantemente en petición de principio de tipo pragmático y dialógico, argumentando a sus oyentes por lo que no podían ellos aceptar. Y el éxito arrasador de sus sermones nos habla de un manejo sin par de estos requisitos. Volvemos a encontrar la presencia de la pragmática y la hermenéutica en la retorica.

Un seguidor de Lulio, Remigio Rufo, nos da en el Renacimiento una lección en cierto sentido negativa, pues nos hace rechazar su empresa. Con lo pesado de los aparatos logicos y logicistas que quiso aplicar a la retórica, y con toda esa lógica combinatoria luliana que pretendio dar al orador para hacer discursos demasiado artificiosos y vacíos, exhibe lo insuficientes que son la sintaxis y la semántica (sobre todo formales) para la acción retórica. Tiene que intervenir, como aspecto pragmático y hermenéutico, la elocución, en ese sentido de ilocución y perlocución de la teorra de los speech acts de Austin, a fin de que pueda ser comprendida y seguida la argumentación.

Por otra parte, la obra de fray Luis de Granada llamó la atención de los estudiosos hacia el hecho siguiente: lo que distingue a la retórica de la lógica es que, además de emplear la argumentación, hace uso de la amplificación, la cual es la forma de engrandecer y embellecer las cosas que uno dice mediante el omato y el toque de los afectos. Hizo ver que en la retórica se fusionan el aspecto descriptivo o constatativo y el performativo, como los llama (en seguimiento de Austin) John Searle. Y lo performativo es algo que pertenece eminentemente a la pragmática del discurso. Está sobresaturado de significado y sólo la pragmática y la hermenéutica pueden esclarecerlo. 
En la modernidad, Pascal, el gran geometra, tensionado por su pensamiento racionalista y lógico, y por "las otras razones", a saber, las del corazón, es un paradigma (en el sentido de Kuhn) de la conjunción que de lo cognoscitivo y lo emotivo se da en la retórica. Y esto es ya rebasar la sintaxis y la semántica sólo encaminadas a lo formal, como son las de la axiomática. Ella de suyo sería la mejor retórica (él pensaba en los Elementos de Euclides) si no interviniera el factor emocional. Por eso, más allá del racionalismo está el hombre total, compuesto de razón y corazón. Hay un ingrediente psicologico fuerte en la argumentación, que, por el miedo al psicologismo, los lógicos relegaron a la pragmática y a la hermenéutica.

Por su lado, Perelman, el maestro reciente de la argumentación dialéctico-retórica, ha enseñado muchas cosas acerca de la pragmática y la hermenéutica de la oratoria. Entre ellas obtiene un lugar primordial su noción pragmática de lo razonable, más concreta que la de lo racional, y la idea de auditorio que está presente en toda argumentación.

Finalmente, antes que Ricoeur, Gadamer ha hablado del componente de virtud o.hábito que tiene la retórica. Puede ser innata, pero también cultivarse o adquirirse por aprendizaje. En ambos casos es un saber cómo y no sólo un saber que (según la distinción cara a Gilbert Ryle y de otra manera a Piaget). También previene sobre el carácter de engaño que puede tener. Es precisamente sobre su aspecto de sofistiquería sobre el que Ricoeur nos ha llamado la atención. La retórica tiene doble filo: puede buscar lo verosímil inclinado a lo verdadero o puede buscar lo verosímil inclinado a lo falaz. Puede ser auténtica o perversa. $Y$, en todo caso, también nos habla de la pretensión que ha tenido la retorica de ser coextensiva a la filosofía, ya que puede tratar de todas las cosas, incluso de las que tratan la dialéctica y la lógica. Pero Ricoeur -y también lo ha hecho Gadamer - nos manifiesta las semejanzas y diferencias de la retórica con la hermenéutica. En todo caso, la principal cercanía de la retórica con la hermenéutica es que una y otra versan sobre un discurso sobredeterminado, so- 
brecargado de significados, cuya riqueza exige el análisis interpretativo más fino y pleno. ${ }^{14}$

\section{Conclusión}

Todo lo anterior nos indica que la retórica es una acción comunicativa demasiado compleja y rica, que colma el análisis semiótico en sus tres dimensiones de sintaxis, semántica y pragmática. Esta última es para ella un requisito indispensable. Y también nos percatamos de que en el discurso retorico tiene cabida de manera igualmente apropiada la hermenéutica, aledaña a la pragmática. Ya otra cosa será preferir la pragmática o la hermenéutica, según se ponga el énfasis en rescatar el significado del hablante en su mayor pureza o mezclado con la subjetividad del intérprete. En todo caso, más sensato parece ayudarse de ambas, y reunirlas en ese entrecruce de intencionalidades que son la del hablante y la del oyente, ambos usuarios y esclavos, a la vez, de la palabra.

14 Ver M. Beuchot y R. Blanco (comps.), Hermenéutica, psicoanálisis y literatura, México: UNAM, 1991. 